\title{
Identification of Infrasound Generation Mechanisms in a Bus
}

\section{Ulf Sandberg}

Reprint from Journal of Low Frequency Noise And Vibration,

Vol 7 No 3 1988, pp 110- 116 
Identification of Infrasound Generation Mechanisms in a Bus

Ulf Sandberg

Swedish Road \& Traffic Research Institute

S-581 01 Linköping, Sweden

\section{Reprinted from}

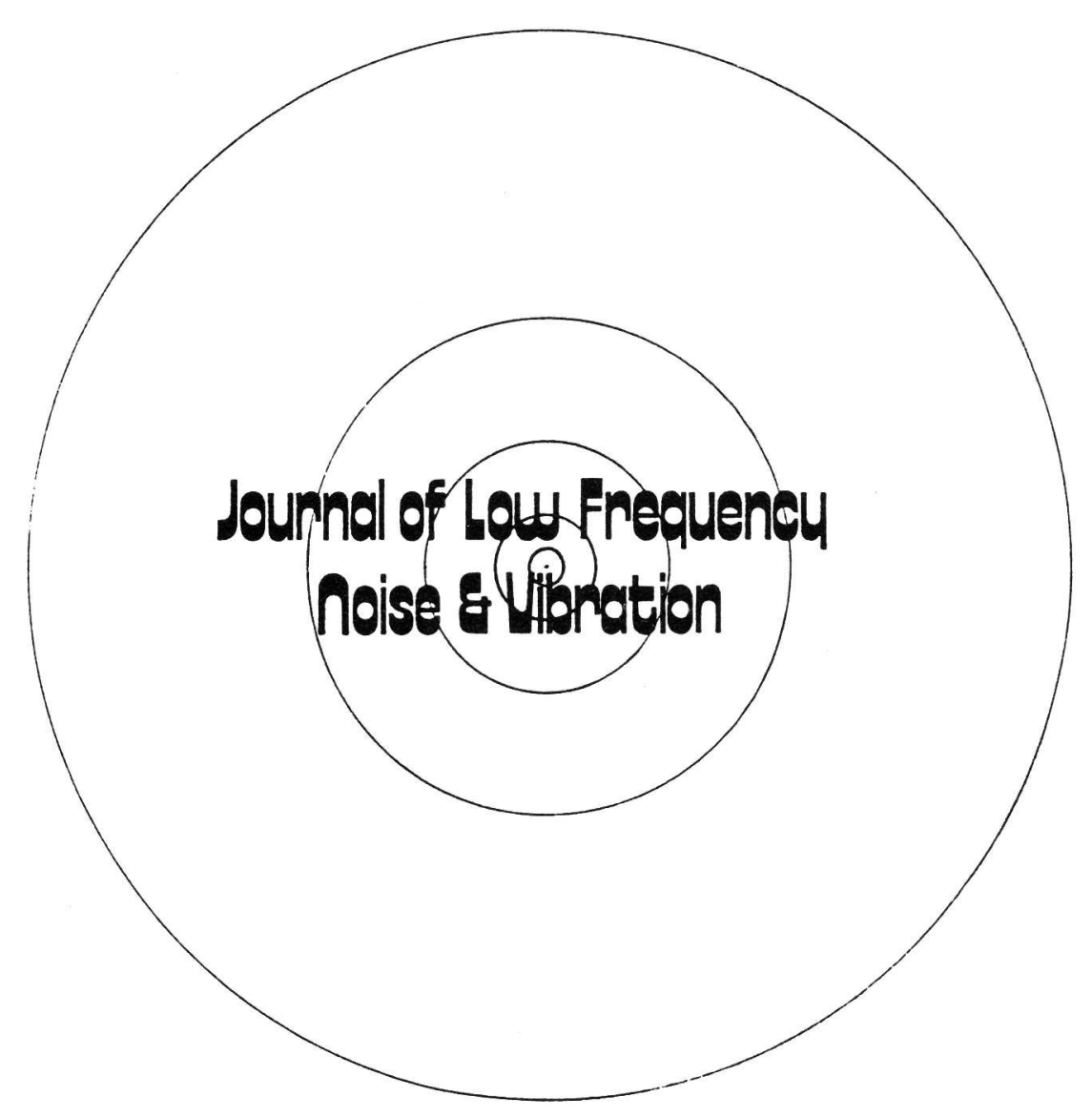

Vol 7 No 31988 



\title{
Identification of Infrasound Generation Mechanisms in a Bus
}

\author{
Ulf Sandberg \\ Swedish Road and Traffic Research Institute, S-58101 Linköping. Sweden
}

(Received 24th Jan 1988)

\begin{abstract}
This paper presents the results of experiments conducted to investigate infrasound generation in a bus. The bus was driven on a smooth road, both upwind and downwind, and with and without damping of window vibrations. It was also run on an uneven road for comparison. The results show that by damping the window vibrations it was possible to reduce the infrasound levels significantly. It is also concluded that higher air turbulence around the bus slightly increases the infrasound outside the frequency range of the axle resonance. Finally, it is concluded that road roughness as well as tyre "roughness" (unbalance or run-out) excite vibration and infrasound.
\end{abstract}

\section{Introduction}

Infrasound in road vehicles has been shown to affect driver performance (Ref. 1). However, the indictions obtained so far on the impact of infrasound on health, performance and comfort are insufficient for the specification of any limiting values. Recently, the National Board of Occupational Safety and Health issued Advisory Notes regarding infrasound in which it is recommended that "exposure levels" be lower than about $5-10 \mathrm{~dB}$ above the threshold of perception in the range $2-20 \mathrm{~Hz}$ (Ref. 2). The philosophy is that if infrasound is lower than or near the threshold there should be no reactions of discomfort, etc.

If these Advisory Notes are taken seriously in practice many transportation activities will be in trouble. For instance. from a survey of infrasound $\mathrm{L}_{\mathrm{e} y}$ measurements at the driver's position in buses in traffic (Ref. 3 ), it appears that 28 out of 30 measurements exceeded the "exposure levels". In fact, most road transportation todat results in infrasound levels that exceed the "exposure levels" given in Ref. 2.

Irrespective of how the above-mentioned Advisory Notes are used, it was concluded in an earlier simulator experiment that in at least a few buses, infrasound emissions are such that they may reduce driver performance (Ref. 1). This is sufficient to initiate work to reduce the infrasound and it is important to understand how this sound is generated in order to take the proper measures. This report deals with infrasound generation in a bus and demonstrates how infrasound may be reduced by damping the vibrations of large, plane windows.

\section{Purpose}

The purpose of this study was originally to investigate the correspondence between measurements of infrasound by various laboratories, and these results are not reported here. Another purpose of the study, which was developed during the test program. was to investigate whether the damping of window vibrations in the bus would have any effect on infrasound or not. The experiment was not directly designed for this, but it turned out that it would also be possible to evaluate the results in terms of infrasound generation mechanisms for this bus.

\section{Test vehicle}

The test vehicle was a Scania BF86 bus with Ajokki 5000B body (model year 1977). It was chosen for this experiment because it was thought to give higher infrasound than "normal" due to some defect. The bus was constructed with large, plane windows as is common on modern buses. See Fig. 1. 


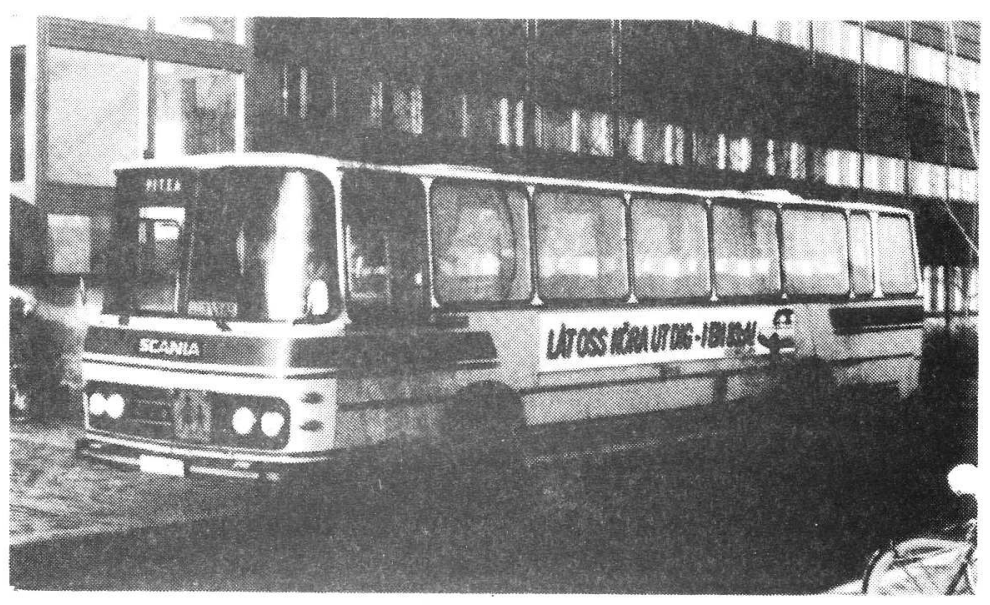

Fig. 1 The test vehicle

Data: Chassis: Scania BF86

Body: Ajokki $5000 \mathrm{~B}$

Age: 5 years in traffic (1977 model)

Owner: Länstrafiken i Norrbotten

Tyres: front axle: Michelin XZA; rear axle: retreaded (E20) block pattern Tyre dimensions: $11.00 \mathrm{R} 20$, rolling circumference $3.31 \mathrm{~m}$

Engine speed for max power: $2400 \mathrm{rpm}$

Vehicle speed for max power (highest gear): $108.8 \mathrm{~km} / \mathrm{h}$

Gear box: Manual 5 years, transmission 1:1.28 on 4th gear, rear axle transm. 1:4.38

Measuring date: 1982-11-30.

\section{Experimental method}

4.1 Measuring system

The measuring system shown in Fig. 2 was used. Due to the wide spectral $(2-20000 \mathrm{~Hz})$ as well as amplitude $(40-120 \mathrm{~dB})$ ranges, the recordings were divided into two parts; one comprising 2-1000 Hz and one comprising 20-20000 Hz. The former was recorded by an FM technique and the latter was recorded directly. The measurements were made at the driver's seat at a position about $0.1 \mathrm{~m}$ to the right of the driver's right ear.

\subsection{Analysis system}

A real-time frequency analyzer of third-octave band resolution was used, see Fig. 2. Calculations of special weighted overall sound levels were made in the computer: These included the following weighting curves:

Lin No weighting

A, C, D Standardized in IEC 179 and 537

DX As D, but everything below $20 \mathrm{~Hz}$ is excluded

IL Linear in the range $2-20 \mathrm{~Hz}$. zero outside this range

G1. G2 Standardized in ISO/DIS 7196

I, II Special curves constructed to correspond to weighting networks in our "infrasound dosimeters"

Marg Margin between the measured spectral levels and the exposure levels (in third-octave bands) as suggested by Ref. 2 . The value given is the level difference in the third-octave band where the measured value is "worst" in relation to the exposure levels.

The measuring and analysis time was $128 \mathrm{~s}(2 \mathrm{~min})$ in each case. This gives a B.T product of 59 at $2 \mathrm{~Hz}$ and 590 at $20 \mathrm{~Hz}$ which provide adequate precision when measuring random infrasound signals such as those generated by road unevenness or wind turbulence. 


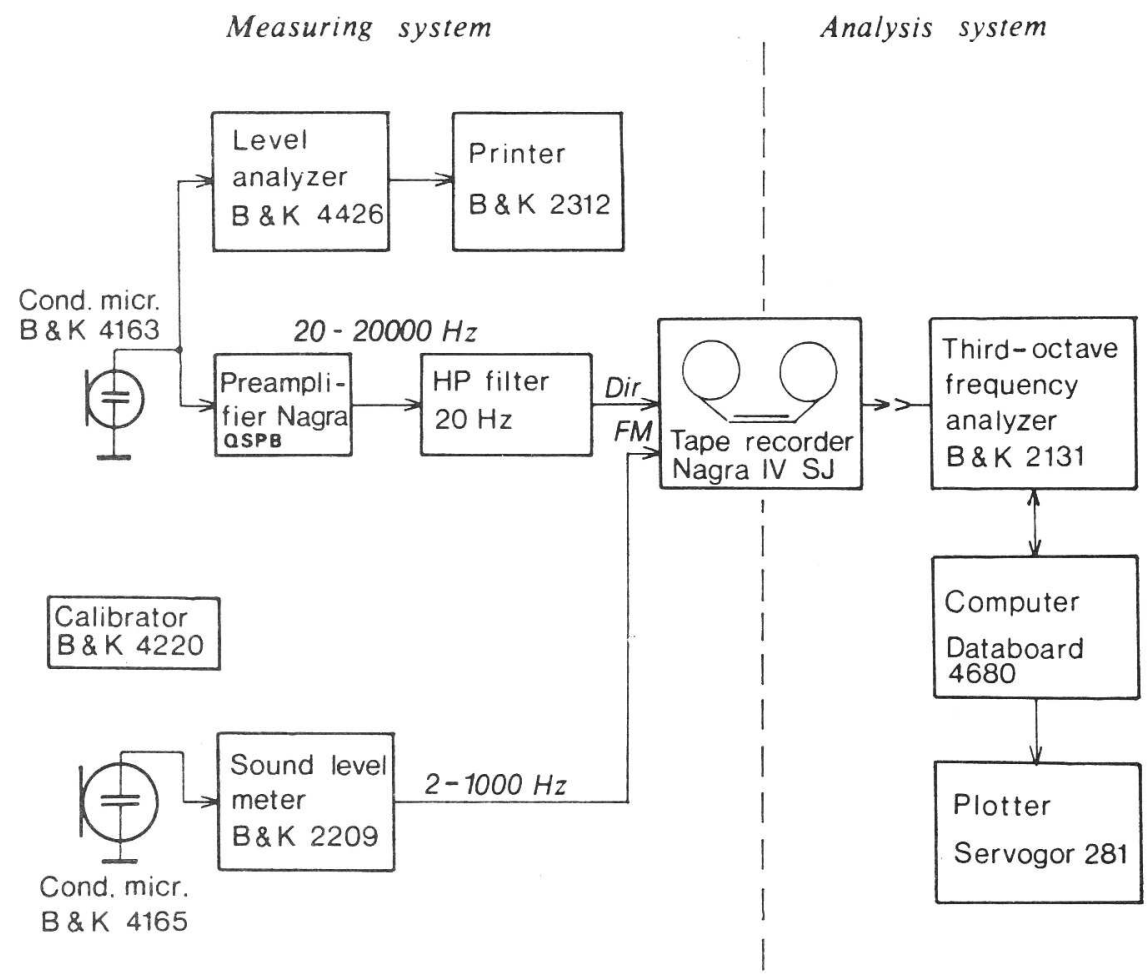

Fig. 2 The measuring and analysis system. The level analyzer and its printer were not used in this experiment. The high-pass filter is mounted in the tape recorder and is used to reduce the risk of overloading the recording due to highamplitude low-frequency signals.

\subsection{Test roads}

The test road was a long straight highway paved with a smooth asphaltic concrete surface (type MAB12T according to the Swedish code). Its unevenness had been measured by the VTI Laser Road Surface Tester and found to be around 1.2 expressed as IRI in $\mathrm{m} / \mathrm{km}$. So, this test road appeared to be quite even.

For comparison one measurement was made on a gravel road with moderate unevenness. As this was narrow and not straight the speed varied between 40 and 50 $\mathrm{km} / \mathrm{h}($ average $44 \mathrm{~km} / \mathrm{h})$. On the IRI scale this road was estimated to have a rating around 4.5 .

\subsection{Test runs}

The following test runs were made:

- $30,50,70$ and $90 \mathrm{~km} / \mathrm{h}$ on gear No. 5 (No. 4 at 30)

- $0.4 \times \mathrm{V}, 0.5 \mathrm{xV}, 0.7 \times \mathrm{V}, 0.7 \mathrm{xV}, 0.8 \mathrm{xV}$ where $\mathrm{V}$ is $108.8 \mathrm{~km} / \mathrm{h}$ (gear No. 5)

- $0 \mathrm{~km} / \mathrm{h}$ (idling) with and without fans

- Accel. test according to ISO (0.45-0.90xV) on gear No. 5

- Accel. test according to SAE (0.5-1.0xV) on gear No. 4

- $70 \mathrm{~km} / \mathrm{h}$ on gear No. 5 . upwind $2.0 \mathrm{~m} / \mathrm{s}$ (overall wind speed rel. to the bus was then $21.4 \mathrm{~m} / \mathrm{s}$ )

- Ditto, with windows damped (pushed by the passengers)

- $70 \mathrm{~km} / \mathrm{h}$ on gear No. 5 . downwind $2.0 \mathrm{~m} / \mathrm{s}$ (overall wind speed rel. to the bus was then $17.4 \mathrm{~m} / \mathrm{s}$ )

- Ditto. with windows damped (pushed by the passengers)

Damping of the windows was accomplished by, at a certain moment. the bus passengers pushing their hands firmly on the centre of the plane windows (except the curved front windows). 
This could not eliminate window vibrations completely, just reduce them to a lower level. It was estimated that the amplitude could be reduced by about $50 \%$ in this way.

\section{Hypothetical sources of infrasound in road vehicles}

Originally, the following were considered as potential sources of infrasound:

- Vibration in the engine or the transmission

- Vibration caused by road roughness

- Vibration in the body caused by turbulent air flow around the bus

- Air turbulence in open windows amplified by a Helmholtz resonator

- Vibration caused by tyre non-uniformity

From earlier, systematic measurements of infrasound spectra in several buses it was concluded that all buses exhibited essentially the same frequency spectra, although the levels differed by up to $10 \mathrm{~dB}$ between the buses. Therefore it is reasonable to believe that the generation mechanisms are basically the same although of different relative importance. The bus chosen here was found to deviate from the norm only due to unbalance or run-out of the tyres.

The generation mechanisms have been investigated and reported earlier (Ref. 3). There it was found that all sources listed above, with exception of the first, were important, although the two most important were vibration in the body caused by road roughness and tyre run out/unbalance.

\section{Results}

Figs. 3 and 4 show the difference in spectra between driving up- and downwind, i.e. wit slightly different wind turbulence around the bus body. It is evident that the more intense turbulence gives a small increase in infrasound for most frequencies except in the range $12-20 \mathrm{~Hz}$ (the axle resonance); the most exceptional being the frequency of the highest peak $(12.5 \mathrm{~Hz})$ where the situation is reversed. The increase must be due to turbulence-induced vibration in the body. It may be speculated that the decrease at $12.5 \mathrm{~Hz}$ may be due to a higher driving load due to the upwind conditions which may damp out unbalance in a tyre such as seems to be the case for the rear-axle tyres on this bus. These tyres were retreaded and by inspection appeared non-uniformly worn.

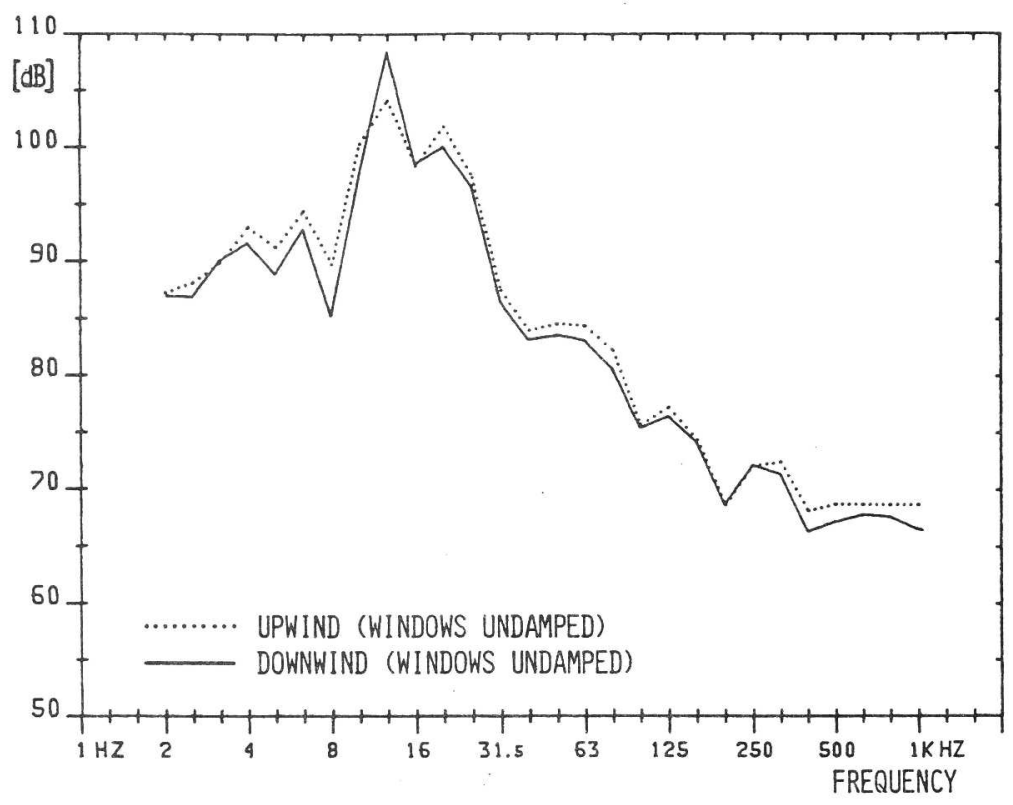

Fig. 3 Spectral changes between driving upwind and downwind (higher and lower air turbulence, respectively). Windows were undamped. 


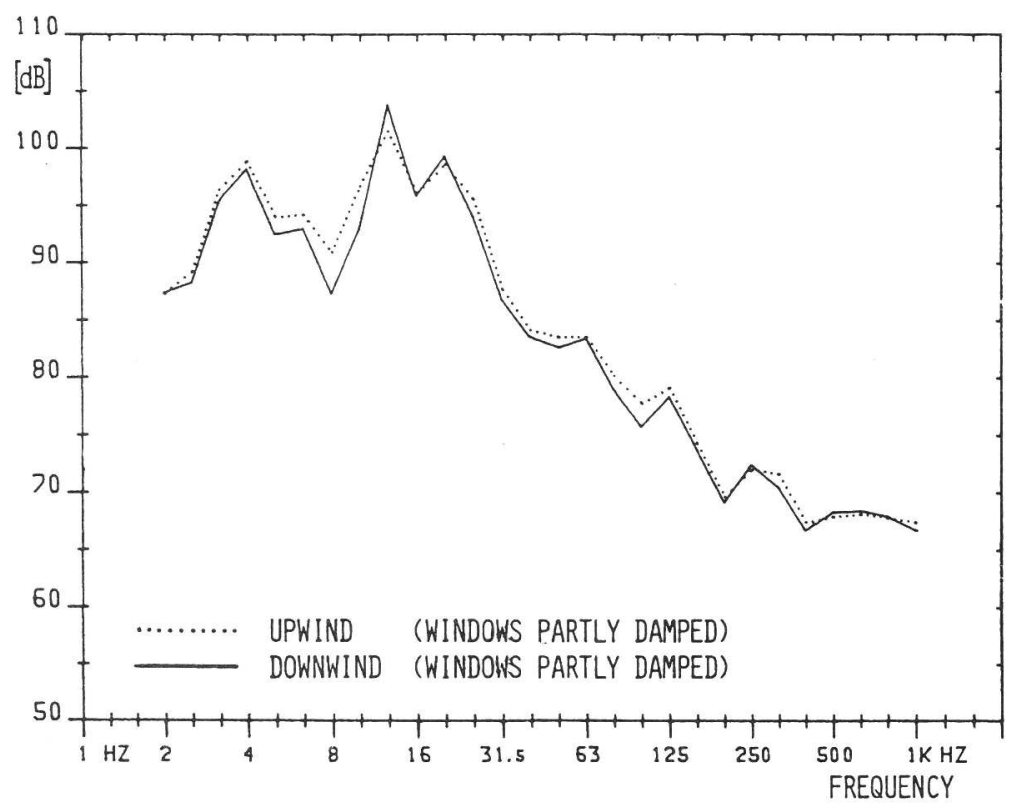

Fig. 4 Spectral changes between driving upwind and downwind (higher and lower air turbulence, respectively). Windows were partly damped.

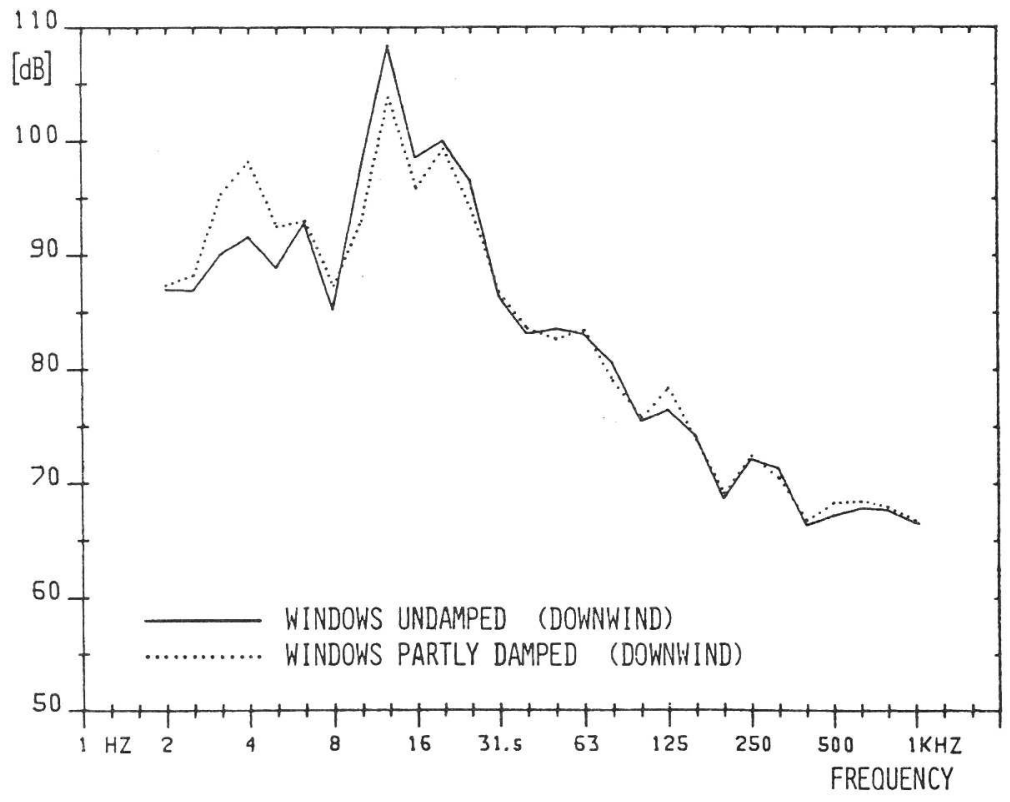

Fig. 5 Spectral changes when the centre of the windows were pushed by hand ("partly damped") relative to the "undamped" case.

Fig. 5 shows the difference in spectra due to the damping of the windows when pushing the centre of them. Two effects may be noted:

- The highest peak at $12.5 \mathrm{~Hz}$ is reduced by about $5 \mathrm{~dB}$ by the "damping

- A new, secondary peak arises at about $4 \mathrm{~Hz}$ where the level is increased by $7 \mathrm{~dB}$

The new secondary peak may be due to a lower natural resonance of the windows when its apparent mass is increased several times by the pushing which was intended to damp the vibrations rather than to move the resonance frequency. Of course, the net effect of the "damping" is clearly positive as the overall level is decreased by $2-3 \mathrm{~dB}$ on the linear weighting scale and by $3 \mathrm{~dB}$ on the newly standardized $\mathrm{Gl}$ weighting scale. 
TABLE I

The overall infrasound levels in $\mathrm{dB}$ with different weightings. Exc $=$ The maximum excess of the measured spectrum over the exposure spectrum proposed in Ref. 1.

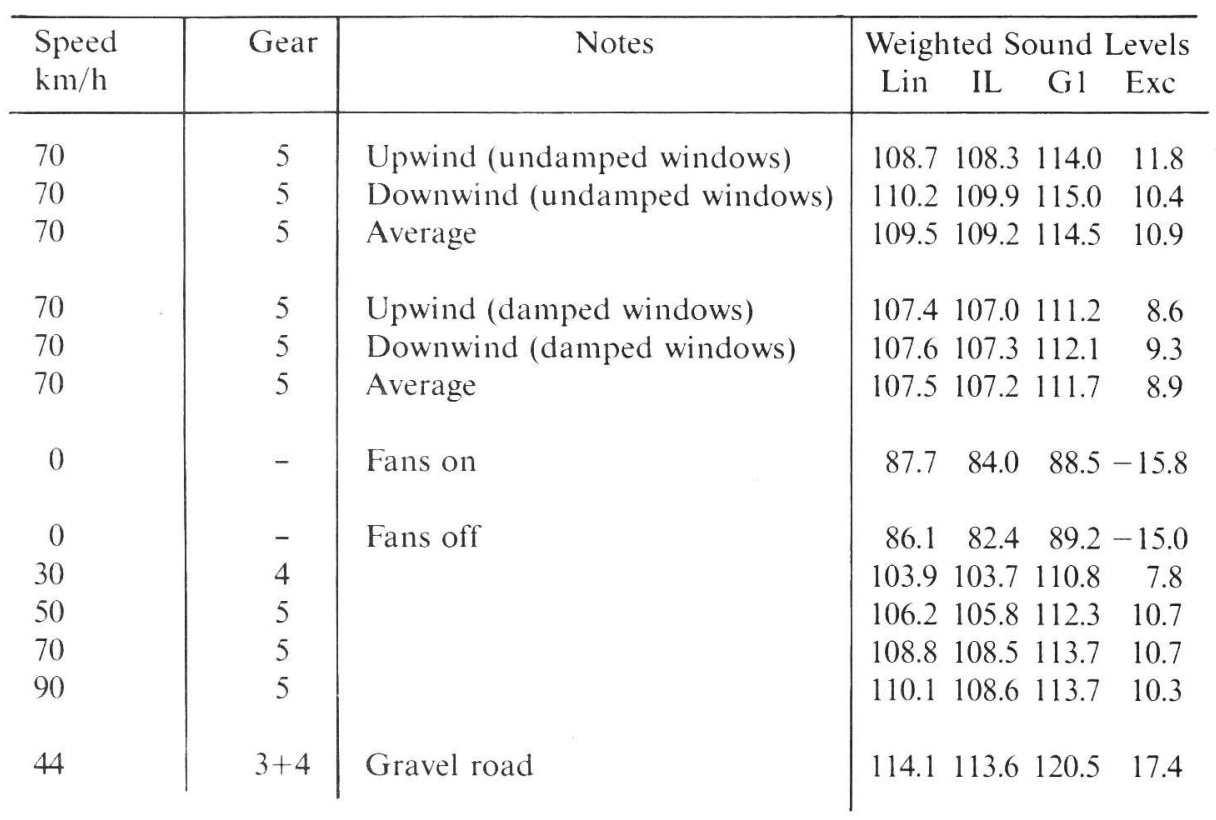

Table I summarizes the overall levels.

The special test to investigate the effect of road roughness on the infrasound showed that this influence is important. In Fig. 6 it is clear that for all frequencies 6-200 $\mathrm{Hz}$ the infrasound is increased by $5-10 \mathrm{~dB}$. The overall level is increased by $8 \mathrm{~dB}(\mathrm{Gl})$ despite the speed being a little higher ( 50 versus average of $44 \mathrm{~km} / \mathrm{h}$ ) in the smooth road case, see Table I.

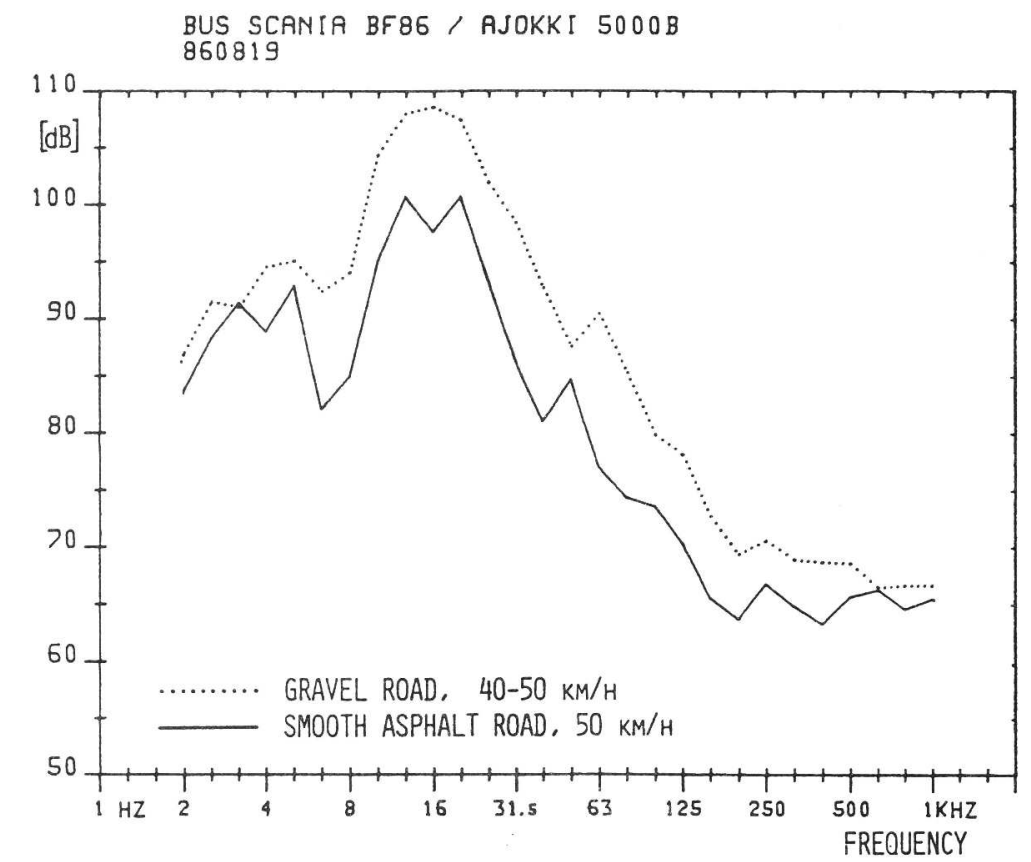

Fig. 6 The difference in infrasound when driving on a smooth asphalt road and a rough gravel road. 
Earlier (Ref. 3), it has been shown that tyre run-out (i.e. the tyre is not circular) and unbalance excites body vibrations and infrasound. In Fig. 7 the very pronounced resonance $12.5 \mathrm{~Hz}$ at the speed of $70 \mathrm{~km} / \mathrm{h}$ coincides closely with twice the tyre rotation frequency $(11.7 \mathrm{~Hz})$. It seems that when a multiple of two or three times the tyre rotation frequency comes into the frequency range of axle resonance. then a high peak may be expected. It was noted in an earlier test programme that the use of retreaded tyres very often resulted in tyre run-out or unbalance with accompanying high infrasound levels. And, of course, to the bus body, roughness in the tyre and the road should have similar effects. Visual inspection showed that the tyre tread on the rear axle tyres was worn in a non-uniform manner.

The high peak at $31.5 \mathrm{~Hz}$ at $90 \mathrm{~km} / \mathrm{h}$, which is outside the traditional infrasound range, is likely to be associated with the bus engine frequency which is $33 \mathrm{~Hz}$ at this speed (harmonics of two and three times this frequency are also visible).

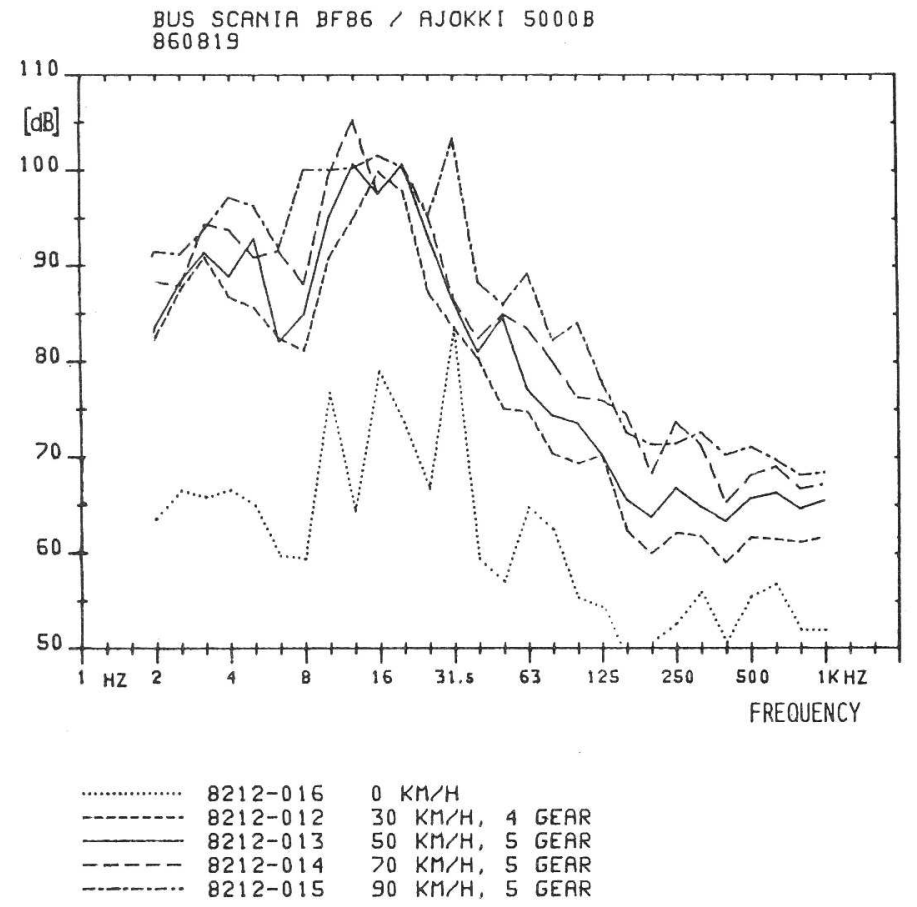

Fig. 7 The trequency spectra for different driving speeds

\section{Conclusions}

7.1 Higher air turbulence around the bus appears to slightly increase the level of infrasound at most frequencies outside the range of the axle resonance (12-16 $\mathrm{Hz}$ ). However, the big difference at very low frequencies $(2-5 \mathrm{~Hz})$ as reported in Ref. 3 was not observed for this bus.

7.2 By pushing by hand the centres of the plane windows in the bus it was possible to influence the infrasound. The overall infrasound level was decreased by $3 \mathrm{~dB}$ (G1-weighted) by this simple activity. However, it seemed that the result was caused mainly by a removal of the window resonance to a lower and less sensitive frequency. rather than by really "damping" the vibrations. Both effects could of course be present. This clearly demonstrates that infrasound may be easily abated by changing the window resonances.

7.3 Road roughness or unevenness has a pronounced influence on infrasound generation. It means that the roughness excites axle vibrations which are transmitted to the body and radiated from the large panels in the bus as infrasound. 


\section{INFRASOUND GENERATION IN A BUS}

7.4 Similarly, "roughness" in the tyres (unbalance or run-out), which especially seems to be associated with retreaded tyres, may excite vibration and infrasound.

\section{Recommendations}

When abating infrasound in buses, efforts should be made to separate the axle or suspension resonance, window natural frequencies, tyre unbalance or run-out frequencies (especially their harmonics), engine rotation frequency and the cabin air resonance mode (half the wavelength equals the cabin length). In certain circumstances all these may coincide to give high infrasound levels. Since human perception is more sensitive to the higher infrasound frequencies, it is preferable to shift the resonances to lower frequencies, if possible.

A first, quite simple step, would be to increase the damping and/or change the natural frequencies of the large windows in the bus. Another effective step would be to check non-original tyres for run-out or unbalance.

\section{References}

1. Sandberg, U. Combined Effect of Noise, Infrasound and Vibration on Driver Performance. Proceedings of Inter-Noise 83 in Edinburgh, pp 887-890 (Also reprint No. 86, Swedish Road and Traffic Research Institute).

2. Arbetarskyddsstyrelsens kungörelse med föreskrifter om buller (requirements regarding noise). AFS 1986:15. The National Board of Occupational Safety and Health, Stockholm, 1986-08-20.

3. Sandberg, U.: The Generation of Infrasound in Buses. Proceedings of Inter-Noise 81 in Amsterdam, pp 727-732. (Also reprint No. 65. Swedish Road and Traffic Research Institute). 


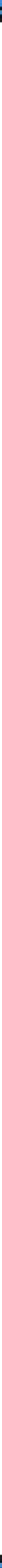

